\title{
Short review on PM-bound water. Its presence in the atmosphere, forms of occurrence and determination by Karl Fischer coulometric titration
}

\author{
Kamila Widziewicz ${ }^{1, *}$, Malwina Tytła $^{1}$, Patrycja Rogula-Kopiec $^{1}$, \\ and Wioletta Rogula-Kozłowska ${ }^{1}$ \\ ${ }^{1}$ Institute of Environmental Engineering Polish Academy of Sciences, 34 Marii Skłodowskiej-Curie \\ St. 41-819 Zabrze, Poland
}

\begin{abstract}
Literature data indicate, that the conversion of secondary PM (particulate matter) precursors are largely controlled by the amount of atmospheric water vapor, and that higher capacity of water accumulation is demonstrated mainly by fine particles of anthropogenic origin, rich in ionic compounds like sulfates, nitrates, ammonia and chlorides, arising for example from biomass incineration processes. Smaller retention capability is however typical for coarse PM particles of natural origin, containing lot of crustal material like aluminosilicates. It is therefore suspect that both the size of PM particles and the source of its origin will determine its hygroscopicity. The quantitative and qualitative measurements of water contributions in PM for example by means of Karl Fischer titration method could be therefore a good marker of PM origin. Due to analytical limitations the identification of water contents in PM and the differences in water fingerprint between PM collected in different locations is still quite challenging.
\end{abstract}

\section{The presence of water in the atmospheric PM}

An important parameter in determining chemical composition of atmospheric PM is its water content. The amount of water in PM particles affects: the processes of clouds formation $[1,2]$, atmospheric visibility (by influencing PM light scattering properties) [3, 4], its washout from the atmosphere, as well as particles deposition onto the ground. Some particles due to their hygroscopic properties takes also part in the formation of clouds (they become a cloud condensation nuclei also known as cloud seeds). If the hygroscopic nuclei are numerous, water vapor rapidly condenses on them, leading to an increase in rainfalls over the cities due to the particulate air pollution [5]. Depending on the location and the size of the PM particles the amount of water in PM can vary from few to several tens of percent [6-8]. According to the model estimates done by [9], the fraction of $\mathrm{PM}_{2.5}$-bound water at 50\% RH (relative humidity) varies across Europe between $20 \%$ and $35 \%$. However

* Corresponding author: kamila.widziewicz@ipis.zabrze.pl 
model calculations at $50 \% \mathrm{RH}$, made by [10] reported a somewhat lower water content (13-23\%) for $\mathrm{PM}_{2.5}$ in Switzerland. Weighing samples at a lower RH (about 20\%), resulted in a lower water content $(<10 \%)$ in Duisburg, Prague, Amsterdam and Helsinki.

The current state of knowledge indicate, that PM rich in sulfates, nitrates, ammonium nitrate, chlorides [11-13] or dicarboxylic acids [14, 15] possess greater tendency for water absorption compared to those containing sand and soot [16]. Results from thermodynamic modelling indicate that $\sim 80 \%$ of PM-bound water originate from $\mathrm{SO}_{4}{ }^{2-}$ and $\mathrm{NO}_{3}{ }^{-}$ compounds [17], while the remaining $20 \%$ is usually attributed to the residual water incorporated into organic matter [15]. The chemical aging of initially insoluble or slightlysoluble compounds of OA (organic aerosol) under the influence of water vapor may enhance their solubility and hygroscopicity, making them more active cloud CCN (cloud condensation nuclei) - very susceptible to wet deposition [18]. For example, tests conducted in the Great Smoky Mountains National Park in 2006 [19] indicate, that organic carbon bonded to $\mathrm{PM}_{2.5}$ particles can absorb up to $5 \%$ water under conditions of $45 \% \mathrm{RH}$ humidity of and up to $33 \%$ under humidity close to $80 \% \mathrm{RH}$. The effect of the RH on the aerosols hygroscopicity is important in obtaining more reliable estimates concerning its chemical transformations, the formation of the secondary PM species starting from gaseous precursors and PM migration in the environment. For example high values of relative humidity $(\mathrm{RH})$ favor the occurrence of acid-base reactions leading to the formation of secondary inorganic salts $[20,21]$. When ambient relative humidity $(\mathrm{RH})$ reaches the deliquescence point [22] inorganic salts becomes liquid, although under low RH and high air temperature water evaporate from PM surface causing crystallization of ionic compounds. It has been proven that PM particles contain significant amounts of water, even when $\mathrm{RH}$ is less than $20 \%$ and that acidic water vapor serves to increase the hygroscopicity of the PM [23].

\section{Forms of water occurrence in PM}

Many studies conducted worldwide tried to assess chemical composition of PM matter, which is generally the sum of different compounds like: sulfates, nitrates, organic carbon, elemental carbon, crustal material, metals and hydrocarbons. The mass closure of those compounds - ratio of the reconstructed chemical mass to the gravimetrical mass - indicate however that this sum does not give $100 \%$ by weight and usually account for $70-90 \%$ of the $\mathrm{PM}_{2.5-10}$ mass. The remaining mass is partially attributed to mentioned aerosol-bound water. Owing to practical analytical limitations [24], most networks do not measure liquid water in PM samples. As a result, the sum of the PM species is often lower than the PM gravimetric mass [9, 25-28]. Basically, the water in PM occurs as loosely associated (weakly bound) water, but also as a constitutive (crystallization water) - tightly bound to particles structure. The weakly-bonded water is the water, which condenses on the aerosol particles when the relative humidity $(\mathrm{RH})$ increases, while the bounded one is water remained enclosed in PM compounds. Constitutional water - embedded in the compound may undergo removal only under higher temperatures, or under the influence of dehydrating agents. The removal of the built-in (constitutional) water leads to the formation of another chemical compound [29], for example dehydration of cellulose lead to the elemental carbon, while dehydration of oxyacids to the anhydrides. This water has a precise position in the crystal lattice and is generally directly linked to the cation by coordination bonds. Crystal water is released during heating in a staggered manner; during w new solid phases are formed.

Water absorption resulted to be relevant especially for fine particles, characterized by a well-developed surface area [30-32]. The research conducted for example in six European countries indicate that the unidentified part of the $\mathrm{PM}_{2.5-10}$ mass, which comprised 
probably of aerosol-bound water varies from 4 to $23 \%$ [30]. Due to a smaller amount of hygroscopic compounds in $\mathrm{PM}_{2.5-10}$ it was stated [30] that the contribution of aerosolbound water in this fraction is much smaller than in $\mathrm{PM}<2.5 \mu \mathrm{m}$. They also found that less water is commonly observed in the summer due to low relative humidity. It is also documented that the formation of secondary hydrophilic aerosols and their growth is the main cause of mists occurrence in the heavily polluted regions [34]. Under increasing number of airborne particles and so the likely condensation nuclei - water vapor condenses on them, leading to precipitation [5]. This phenomenon is especially common in large cities - heavily polluted by gas precursors and fine particulate matter. Inorganic salts are strongly hygroscopic and can act as cloud condensation nuclei (CCN), which favour the formation of clouds and fogs. Coarse particles $(>10 \mu \mathrm{m}$ diameter) produced by mechanical processes such as the crushing and grinding of ore, soil resuspension via wind erosion and mechanical disturbance for example driven by agricultural activities typically contain low amounts of water. It's because those particles are generally dominated by crustal matter ( $\mathrm{Si}, \mathrm{Al}$ ), carbonaceous material and sea-salt characterized by a weak polar affinity. Exact opposite situation concern fine $(\leq 2.5 \mu \mathrm{m})$ and accumulation mode particles $(0.1-2.5 \mu \mathrm{m})$ produced mostly by human activities, for example during combustion processes, through the condensation of high temperature vapours. Such particles are rich in organic carbon and salts, and therefore highly hygroscopic. Water mass loading of PM result however not only from its chemical composition but also from the time, which PM spends in the atmosphere, so-called residence time. Coarse and fine particulates have widely varying residence times, and as a result, widely varying distributions [35].

Since fine PM stays in the atmosphere even for a few weeks, and can travel long distances, its contact with water vapor is relatively long, which favours water uptake. In contrast to the sub-micron fine particles, coarse particulates due to their larger settling velocity have a much shorter atmospheric residence time, typically minutes to hours, hence the amount of water remaining on their surface is thereof much less [36]. The contents of weakly bounded water changes fluently depending on the multiply atmospheric conditions. This water is subjected to a rapid quantitative changes, even during the storage of PM filters in a constant laboratory conditions. Thus, the amount of weakly bound water molecules cannot be treated as a marker of PM origin. Some part of the water bound to PM structure is however relatively constant in the conditions prevailing naturally in the atmosphere and this amount is known as a constitutive water. Such binding is characteristic for each chemical compound and thus different components of PM capture this water in other ways. The temperature-controlled heating graphs of different PM samples shows that free water is desorbed at lower temperatures than bounded water [37]. Therefore the proper evaluation of PM-bound water allows not only to perform the PM mass reconstruction but also helps to identify the sources of its origin, since the major components of PM like organic matter (OC), elemental carbon (EC), secondary ions or crustal material absorbs water differently. Nowadays the thermal ramp techniques (selective desorption of different water contributions) helps to apportion different chemical species (retaining water with different strength) to certain groups of compounds (certain emission sources) [7]. While testing water contents in Certified Material NIST 1649a (atmospheric particulate material) using thermogravimetry [26] found, that different water species are released in distinct temperature ranges. The first two sharp weight losses were observed in the temperature ranges $80-120^{\circ} \mathrm{C}$ and $150-180^{\circ} \mathrm{C}$, then two wide weight losses were recorded in the range $180-400^{\circ} \mathrm{C}$ and $400-600^{\circ} \mathrm{C}$. When comparing the results from this analysis with the chemical analysis of the residual matter after different temperature hold times, they found that at $120^{\circ} \mathrm{C}$ the concentration decrease of the inorganic ions was negligible, showing that this range cannot be attributed to inorganic ions. Previous studies also showed that the release of organics occurs in the first three temperature ranges, while at temperatures above 
$500^{\circ} \mathrm{C}$ dust pyrolysis arises [38]. At $180^{\circ} \mathrm{C}$, instead, the mass amount of sulfate remained unchanged, while a progressive decrease of chloride, nitrate and ammonium residual amounts was observed. Atmospheric ammonium salts and organic carbon of secondary origin or sodium salts, of mainly natural origin, show a different thermal behaviour. For example in case of $\mathrm{CuSO}_{4} \times 5 \mathrm{H}_{2} \mathrm{O}$ water desorption occurs in three stages: first stage - two water molecules are desorbed at temperatures up to $80^{\circ} \mathrm{C}$. Between $100-120^{\circ} \mathrm{C}$ another two molecules are desorbed. The last molecules are split off above $180^{\circ} \mathrm{C}$. It is therefore justified that PM from different sources (for example industrial, mobile or stationary) will be retaining water differentially, depending on chemical composition. The results of several preliminary studies show that a simple comparison of the PM evaporation spectra with the gradual water desorption by an individual PM components and finding their similarities may indicate probable common source of origin. Based on qualitative or semi-quantitative comparison of those spectra the released water can be divided into weakly-bounded water desorbed in low temperatures, originating from secondary organic carbon (SOC) and inorganic ions, which mostly originate from coal and wood combustion, followed by road traffic; while those released in higher temperatures can be related to silicates or soot compounds. These conclusion open the new perspective of the use of thermal desorption techniques for the discrimination of natural and secondary contributions to inorganic PM. By using the temperature-controlled heating device it is therefore possible to categorize the released water into specific emission sources and to distinguished between water in the surface - adsorption phase and integral (bounded) water.

In recent years, considerable attention was paid to the development of new methods and models for the proper identification of PM origin. Any cost-effective air pollution control policy cannot be planned without a robust knowledge of the main contributors to atmospheric aerosol concentration. The high number of possible sources and the fast variations of their relative contribution to the atmospheric aerosol make this goal attainable only if the highest possible number of information about particle dimension, shape and chemical composition are known. Apart from this the characteristics of the sampling sites and meteorological situation during the observation periods are also important. Despite the significant progress made in this regard, particularly important from the point of view of PM induced health effects the knowledge concerning the origin of fine PM (mainly $\mathrm{PM}_{2.5}$ and $\left.\mathrm{PM}_{1}\right)[39,40]$ it still relatively low [41]. This especially applies to the Polish territory, for which there is no comprehensive research and studies in this subject. Long-term observation of trends, variability in physiochemical composition of aerosols, including the water contents and supported by detailed analysis of atmospheric circulation, the history of air masses and the share of individual sources of emissions in shaping the PM concentrations in specific locations are the key issues necessary for a full understanding of the transformation of aerosols in the atmosphere, and predicting the effects of their presence (including climate change and long-term health effects). Accurate apportioning of pollutant sources and their components is a critical step toward developing efficient control strategies and reducing the harmful effects of PM [42]. The research on PM content in a source-receptor arrangement in different latitudes revealed that its amount is influenced by both local and long range emissions [43, 44]. Some studies coupled the results from source apportionment models with the surface wind direction and air-mass back trajectories to obtain reasonable estimates of possible sources of PM [45, 46]. However, none of those used a water-contents data to support the inference about its probable origin. Therefore, the identification of water contents in PM and the differences in water fingerprint between PM collected in different locations is a quite challenge. Scientific information on the variability and contents of water in aerosols, originating from different sources is still scarce and such studies have never been performed in Poland before. In spite of the relevant role played by water in the study of atmospheric PM, a quantitative determination of adsorbed water was 
attempted only in a few papers [7, 47, 48]. The current expectations concerning indication the probable origin of PM, especially in highly polluted region of Poland require the usage of better indicators of its probable sources than only the simple measurements of PM concentrations or the usage of back trajectory data. The diagnostic tools like concentration roses, or the direction of air masses inflow are simply not sufficient to properly tracked air pollution. Therefore the knowledge of physical and chemical properties of PM compounds between the source and receptor is very useful [49]. Such knowledge allows to pass from the so-called areas representativeness (stationary sampling points) to the spatial concentrations distribution. The number of papers on the usage of chemical tools for tracking the role of individual PM emission sources (including both local and remote sources) in the formation of water concentrations in ambient PM, is extremely small.

\section{PM-bound water determination by Karl Fischer coulometric titration}

For many years a well-known loss of drying method was used for moisture determination. Apart from low accuracy, especially in case of low mass samples containing trace amounts of water this method take many hours to be completed. The development of Karl Fischer titration method allowed to exclude these difficulties. One of the technique which allows to determine PM-bound water even in trace quantities (ppm to several percent of mass) is Karl-Fischer coulometric titration. This analytical method is a version of the classical water determination method, developed by Karl Fischer. The reaction between the titrant and the sample can be described by the following reaction:

$$
\mathrm{H}_{2} \mathrm{O}+\mathrm{I}_{2}+[\mathrm{RNH}] \mathrm{SO}_{3} \mathrm{CH}_{3}+2 \mathrm{RN}<=>[\mathrm{RNH}] \mathrm{SO}_{4} \mathrm{CH}_{3}+2[\mathrm{RNH}] \mathrm{I}
$$

To measure water contents in solid samples like PM collected on a fibre material a classical titration set is equipped with an oven. In Karl Fischer oven method PM sample is closed in a special vial with a septum in an aluminum crimp cap and is heated to a temperature above $100^{\circ} \mathrm{C}$ under a stable flow of dry intert gas like nitrogen or argon. The released water is than carried by this gas and tranfered into Karl Fischer titration vessel containing methanol. Some types of Karl Fischer instruments allows also to provide a special analysis by utylizing so called ramp temperature programming that can differentiate surface from bound water or distinguished water originating from different PM compounds - for example coal bound water, silica bound water, water associated with sulfates and nitrates and so on. A confirmation of the experimental method could be found in [7], who sucessfully separated different form of water from PM samples by integrating traditional Karl Fischer method with a an optimized thermal ramp program (three heating steps: $50-120^{\circ} \mathrm{C}, 120-180^{\circ} \mathrm{C}, 180-250^{\circ} \mathrm{C}$ ). An identification of the type of the released water was done by applying the same evaporation programme to some hygroscopic compounds that are likely contained in $\mathrm{PM}$ (pure $\mathrm{SiO}_{2}, \mathrm{Al}_{2} \mathrm{O}_{3}$, ammonium salts, carbohydrates and dicarboxylic acids) and by comparing the results with those obtained from field samples. A detailed metrological aspects of this method could be found in [7, 27, 50]. A hygroscopicity of quartz fiber filters most popularly used for PM collection interferes with determination of water content in PM samples. Our research group proposed a new method which allows to avoid the artefacts related to water bound to quartz filters [51].

This work was financed by the National Science Centre, Poland in the frame of the Project with the contract no 2016/23/D/ST10/02705. 


\section{References}

1. W.K. Tao, J.P. Chen, Z. Li, Ch. Wang, Ch. Zhang, Rev Geophys, 50 (2012)

2. S.S. Lee, W.K. Tao, C.H. Jung, Advances in Meteorology, 683950 (2014)

3. J. Jung, H. Lee, Y.J. Kim, X. Liu, Y. Zhang, J. Gu, S. Fan, J, Environ. Manage. 90 (2009)

4. W.J. Qu, J. Wang, X.Y. Zhang, D. Wang, L.F. Sheng, Atmos. Res. 153 (2015)

5. F.K. Lutgens, E.J. Tarbuck, The Atmosphere. An Introduction to Meteorology (Pearson Education Inc. New Jersey, 2004)

6. I.N. Tang, Deliquescence properties and particle-size change of hygroscopic aerosols (Abstracts of Papers of the American Chemical Society, 1979)

7. S. Canepari, C. Farao, E. Marconi, C. Giovannelli, C. Perrino, Atmos. Chem. Phys. 13 (2013)

8. J. Chen, S. Qiu, J. Shang, O.M.F. Wilfrid, X. Liu, H. Tian, J. Boman. Aerosol Air Qual. Res. 14 (2014)

9. S.G. Tsyro, Atmos. Chem. Phys. 5 (2005)

10. C. Hueglin, R. Gehrig, U. Baltensperger, M. Gysel, C. Monn, H. Vonmont, Atmos. Environ. 39 (2005)

11. M. Gysel, J. Crosier, D.O. Topping, J.D. Whitehead, K.N. Bower, M.J. Cubison, P.I. Williams, M.J. Flynn, G.B. McFiggans, H Coe, Atmos. Chem. Phys. 7 (2007)

12. A. Khlystov, M. Lin, M.A. Bolch, Y Ma, Atmos. Environ. 43 (2009)

13. D. Hu, J. Chen, X. Ye, L. Li, X. Yang, Atmos. Environ. 45 (2011)

14. A.S. Ansari, S.N. Pandis, Int. J. Environ. Sci. Technol. 34 (2000)

15. R.E. Speer, E.O. Edney, T.E. Kleindienst, J. Aerosol. Sci. 34 (2003)

16. G.J. Engelhart, L. Hildebrandt, E. Kostenidou, N. Mihalopoulos, N.M. Donahue, S.N. Pandis, Atmos. Chem. Phys. 11 (2011)

17. L-W.A. Chen, B.G. Doddridge, J.C. Chow, R.R. Dickerson, W.F. Ryan, P.K Mueller, J. Air Waste Manage. Assoc. 53 (2003)

18. J.H. Slade, R. Thalman, J. Wang, D.A. Knopf, Atmos. Chem. Phys. 15 (2015)

19. D. Lowenthal, B. Zielinska, B. Mason, S. Samy, V. Samburova, D. Collins, C. Spencer, N. Taylor, J. Allen, J. Geophys. Res. (2009)

20. B.H. Baek, V.P. Aneja, Q. Tong. Environ. Pollut. 129 (2004)

21. S. Squizzato, M. Masiol, A. Brunelli, S. Pistollato, E. Tarabotti, G. Rampazzo, B. Pavoni, Atmos. Chem. Phys. Discuss. 12 (2012)

22. I.N. Tang, Abstracts of Papers of the American Chemical Society, Brookhaven National Laboratory (1979)

23. Z. Wu, W. Birmili, L. Poulain, L. Poulain, M. Merkel, B. Fahlbusch, D. van Pinxteren, H. Herrmann, A Wiedensohler, Atmos. Chem. and Phys. 13 (2013)

24. J.C. Chow, D.H. Lowenthal, L.W. Chen, X. Wang, J.G Watson, Air Qual. Atmos. Health, 8 (2015)

25. R. Balasubramanian, W.B. Qian, S. Decesari, M.C. Facchini, S. Fuzzi, J. Geophysi. Res. 108 (2003)

26. C. Perrino, S. Canepari, M. Catrambone, Aerosol Air Qual. Res. 13 (2013)

27. C. Perrino, E. Marconi, L. Tofful, C. Farao, S. Materazzi, S Canepari, Atmos. Environ. 54 (2012) 
28. M.G. Perrone, B.R. Larsen, L. Ferrero, G. Sangiorgi, G. De Gennaro, R. Udisti, R. Zangrando, A. Gambaro, E. Bolzacchini, Sci. Tot. Environ. 414 (2012)

29. R. Ikan, Springer Science + Business Media Dordreach (2003)

30. R.E. Speer, H.M. Barnes, R. Brown. Aerosol Sci. Technol. 27 (1997)

31. C. Stanier, A. Khlystov, W.R. Chan, M. Mandiro, S.N. Pandis, Aerosol Sci. Techno. 38 (2004)

32. Y. Kitamori, M. Mochida, K. Kawamura, Atmos. Environ. 43 (2009)

33. M. Sillanpaa, R. Hillamo, S. Saarikowski et al., Atmos. Environ. 40 (2006)

34. C.M. Carrico, S.M. Kreidenweis, W.C. Malm, D.E. Day, T. Lee, J. Carrillo, G.R. McMeeking, J.L.J Collett, Atmos. Environ. 39 (2005)

35. S.M Mohan, Int. J. of Environ. Sci. Technol. 13 (2016)

36. A Massling, M. Stock, B. Wehner, Z.J. Wu, M. Hu, E. Bruuggemann, T. Gnauk, H. Herrmann, A Wiedensohler, Atmos. Environ. 43 (2009)

37. C. Farrao, Dissertation. Facoltà di Scienze Matematiche Fisiche e Naturali Dipartimento di Chimica (2014)

38. A. Fushimi, K. Tanabe, S. Hasegawa, S Kobayashi, Sci. Tot. Environ. 27 (2007)

39. G. Hoek, H. Boogaard, A. Knol, J. de Hartog, P. Slottje, et al., Environ. Sci. Technol. 44 (2010)

40. U. Franck, S. Odeh, A. Wiedensohler, B. Wehner, O Herbarth, Sci. Tot. Environ. 409 (2011)

41. M. Cusack, N. Pérez, J. Pey, A. Alastuey, X. Querol, Atmos. Chem. Phys. 13 (2013)

42. A. Tabazadeh, Atmos. Environ. 39 (2005)

43. K. Dimitriou, P. Kassomenos, Atmos. Environ. 96 (2014)

44. C.H. Jeong, M.L. McGuire, D. Herod, T. Dann, E. Dabek-Zlotorzynska, D. Wang, L. Ding, V. Celo, D. Mathieu, G. Evans, Atmos. Pollut. Res. 2 (2011)

45. J.Y. Kima, C.H. Song, Y.S. Ghim, J.G. Won, G.R Carmichael, et al., Atmos. Environ. 40 (2006)

46. A.E. Gildemeister, P.K. Hopke, E.G. Kim, Chemosphere, 69 (2007)

47. S Ohta, T. Okita, Atmos. Environ. 24 (1990)

48. Y.I. Tsai, S.C. Kuo, Atmos. Environ. 39 (2005)

49. A. Daly, P. Zannetti, Ambient Air Pollution, Published by The Arab School for Science and Technology (ASST) and The EnviroCamp Institute (2007)

50. S. Canepari, G. Simonetii, C. Perrino, Atmos. Environ. 165 (2017)

51. W. Rogula-Kozłowska, K. Widziewicz, G. Majewski, Microchem. J. 